Article

\title{
Rural Cooling Needs Assessment towards Designing Community Cooling Hubs: Case Studies from Maharashtra, India
}

\author{
Kumar Biswajit Debnath ${ }^{1, *}++^{(\mathbb{D}}$, Xinfang Wang ${ }^{2,+}(\mathbb{D})$, Toby Peters ${ }^{2, *(\mathbb{D}}$, Sanskriti Menon ${ }^{3}(\mathbb{D})$, Satish Awate ${ }^{3}$, \\ Gaurang Patwardhan ${ }^{3}$, Navneet Wadkar ${ }^{3}\left(\mathbb{D}\right.$, Mahesh Patankar $^{4}$ (D) and Priyanka Shendage ${ }^{4}$ (D) \\ 1 School of Energy, Geoscience, Infrastructure and Society (EGIS), Heriot-Watt University, \\ Edinburgh EH14 4AS, UK \\ 2 School of Chemical Engineering, University of Birmingham, Birmingham B15 2TT, UK; \\ x.wang.10@bham.ac.uk \\ 3 Centre for Environment Education (C.E.E.), Ahmedabad 380054, Gujarat, India; \\ sanskriti.menon@ceeindia.org (S.M.); satish.awate@ceeindia.org (S.A.); \\ gaurang.patwardhan@ceeindia.org (G.P.); navneet.wadkar@ceeindia.org (N.W.) \\ 4 MP Ensystems Advisory Pvt Ltd, Mumbai 400080, Maharashtra, India; mahesh@mpensystems.com (M.P.); \\ priyanka@mpensystems.com (P.S.) \\ * Correspondence: k.debnath@hw.ac.uk (K.B.D.); t.peters@bham.ac.uk (T.P.); Tel.: +44-07917919692 (K.B.D.) \\ + These two authors contributed equally to this work.
}

\section{check for} updates

Citation: Debnath, K.B.; Wang, X.; Peters, T.; Menon, S.; Awate, S.;

Patwardhan, G.; Wadkar, N.;

Patankar, M.; Shendage, P. Rural

Cooling Needs Assessment towards

Designing Community Cooling Hubs Case Studies from Maharashtra, India. Sustainability 2021, 13, 5595. https:// doi.org/10.3390/su13105595

Academic Editor:

George Kyriakarakos

Received: 13 April 2021

Accepted: 14 May 2021

Published: 17 May 2021

Publisher's Note: MDPI stays neutral with regard to jurisdictional claims in published maps and institutional affiliations.

Copyright: (c) 2021 by the authors. Licensee MDPI, Basel, Switzerland. This article is an open access article distributed under the terms and conditions of the Creative Commons Attribution (CC BY) license (https:/ / creativecommons.org/licenses/by/ $4.0 /)$.
Abstract: In a rapidly warming world, sustainable cooling is directly related to the protection of fresh and nutritious food, medicines, and the population from extreme heat for work conditions, the economic productivity of the working population, and income generation. This study aimed to understand how rural communities are meeting their nutrition, livelihood, health, living space, and mobility requirements regarding the role of cooling. We selected three villages as case studies in Maharashtra, India and conducted household surveys, in-depth interviews of key informants, focus group discussions (FGDs), and social mapping building typology study. The objective was to assess the rural community cooling to propose a community cooling hub $(\mathrm{CCH})$ framework that could be economically, environmentally, and socially sustainable for the three villages. Our study showed that agriculture, dairy, buildings (domestic and commercial), and healthcare require cooling intervention in the studied communities. Based on the needs assessment for cooling, we proposed a $\mathrm{CCH}$ framework to provide cooling solutions in an integrated system for rural contexts.

Keywords: community cooling hub; rural community; cooling needs assessment; India

\section{Introduction}

Cooling is inter-linked with several aspects of human health and well-being and is increasingly becoming an essential service in our warming world [1,2]. The protection of fresh and nutritious food [3], medicines, and the population from extreme heat is essential for the human race's survival. Nowadays, cooling has become directly related to work conditions, the working population's economic productivity, and income generation [4]. Enabling universal access to cooling is a multifaceted challenge as fulfilling cooling needs for human well-being may increase energy demand and direct and indirect greenhouse gas (GHG) emissions to meet these needs and cause ozone depletion of refrigerant used by the technologies. The Kigali Amendment to the Montreal Protocol regulates refrigerants' use in cooling technologies and aims to reduce hydrofluorocarbon (HFC) to be less than $15 \%$ by 2036 [5]; China, the USA, and India have not formally ratified this amendment. The protocols also recognise the link between refrigerant transition and the energy efficiency of air-conditioning equipment.

India has more than 3000 cooling degree days per year, one of the highest in the world [6]. Due to extreme heat, the Indian economy is estimated to lose productivity worth 
$\$ 450$ billion by 2030 [7]. Considering temperature projections for the next 50 years and India's geographical location in the tropical region, sector-wise cooling demand is likely to increase manifold. In Tonnage of Refrigeration (TR), the aggregated nationwide cooling demand is projected to grow around eight times by 2037-38 compared to the baseline of the year 2017-18 [8]. As average temperatures increase to scorching and unbearable conditions, India faces the dilemma of meeting the increased needs for cooling for human well-being without increasing GHG emissions. Human-induced climate change in India is expected to continue in the 21st century, with impacts that include 'rise in average temperature; a decrease in monsoon precipitation; a rise in extreme temperature and rainfall events, droughts, and sea levels; and an increase in the intensity of severe cyclones, alongside other changes in the monsoon system' [9]. Krishnan et al. (2020) show a significant increase in the number of warm days and nights, especially over the past 30 years, indicating that these will increase further in the coming years [9]. The Covid-19-pandemic-induced lockdowns in India have also highlighted the need for robust emergency care, disaster preparedness, strengthening localised supply chains, and information systems, especially for the health sector. The shocks and stresses to various economic and societal systems due to Covid 19 have also given indications of the potential role of adaptive, versatile, localised cooling facilities for improving resilience in the future.

Agriculture (food production, livestock, and fisheries), post-harvest produce management (refrigeration, transport, and food processing), health (vaccine and other temperaturesensitive pharmaceutical products and blood storage, transport, space cooling, and comfort), and transport (cars, buses, vans, and freight trucks) need cooling. Furthermore, humans and animals need space cooling for comfort because of extreme temperatures, susceptibility to diseases increases, and work productivity decreases. The productivity of milk animals also reduces during the summer season, leading to economic loss to the owners [10-12]. About $30-40 \%$ of produce gets wasted, resulting in a loss of around INR 920 billion out of 4 million metric tons of fruits and vegetables produced in India [13,14]. Additionally, some animal and human vaccines require cooling [7,11]. Artificial insemination (AI) is used for industrial animal reproduction where cooling is needed to preserve semen in animal husbandry.

To address the challenge of meeting increasing cooling demands while minimising potential emissions, assessing current and future cooling needs in an integrated manner is an essential first step [15]. To assess rural cooling needs (present and future), we collected empirical data across various sectors in three villages in Nashik and Satara districts, Maharashtra, India, during 2019-2020. The study was a pilot project, but the methodology and proposed solutions could be applied to other rural areas in the global south to identify and assess the local communities' cooling needs. Section 2 introduces the methods and data collected for the study. After analysing the data and results in Section 3 of the paper, and a community cooling hub (CCH) $[16,17]$ design is presented and discussed in Section 4 with key messages concluded in Section 5.

\section{Materials and Methods}

Three villages of western Maharashtra state were selected for the needs assessment study: Koregaon of Satara district and Sinnar and Yeola from Nashik district (Figure 1), which were selected according to village population size and area, considering the potential to fully utilise cooling infrastructure with sizes based on recommendations by National Centre for Cold Chain Development (NCCD) in India [18]. Access to the field and local stakeholders to enable data collection, non-governmental organisations (NGOs) presence, and developmental interventions are also considered in selecting the case study villages. Aiming to identify the different sectors at present and prospective sectors in the future that require cooling in the context of selected rural communities, and understand drivers and barriers in addressing cooling demands, mixed methods covering both quantitative and qualitative data collection are used in this study (Figure 2). The primary data collection 
tools included household survey, in-depth interviews of key informants, focus group discussions (FGDs), social mapping, and building typology study.

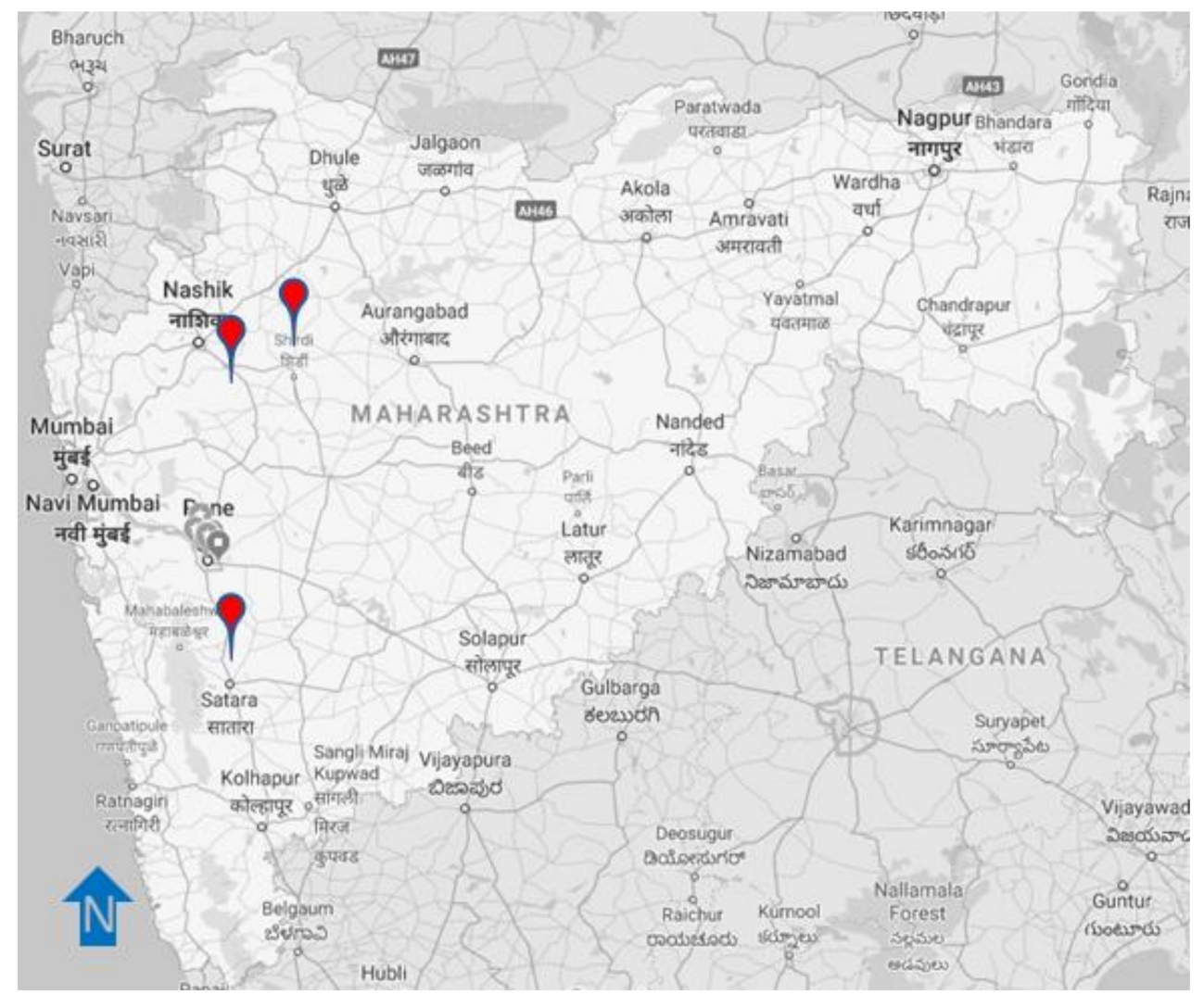

Figure 1. Case study locations (red pins) in Maharashtra, India; map source: Google Earth.

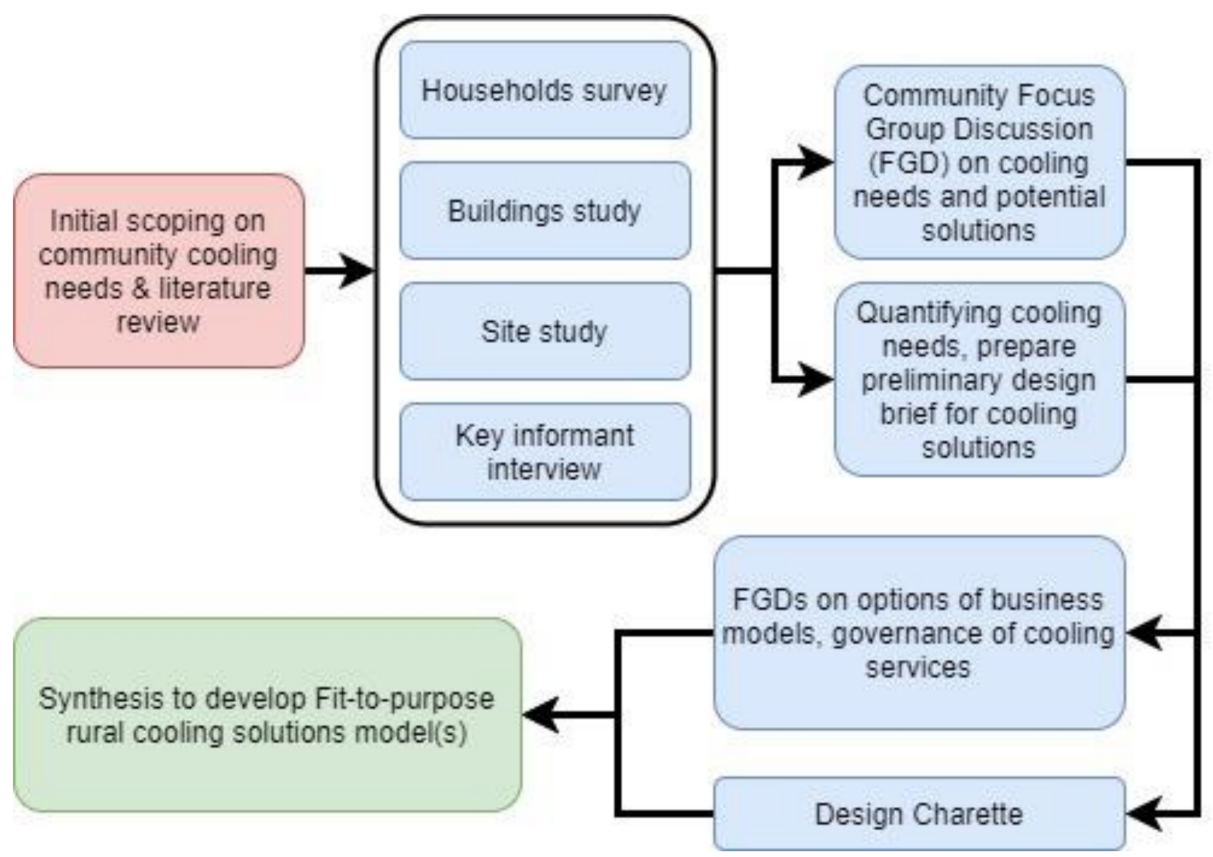

Figure 2. Study methodology.

The household survey tool included quantitative and qualitative questions to identify and quantify community-wide cooling needs, losses due to the absence of cooling, and demand for cooling at household and community levels. Qualitative questions were 
included in the interview schedule to fill gaps in quantitative data; they mainly addressed the 'why' and 'how' questions to understand the processes around cooling needs and how they were met (or not). Key informant interviews and site observations were deployed in parallel with household surveys. In-depth interviews were conducted with key informants from the village such as Sarpanch (Head of the village), Auxiliary Nurse Midwife (A.N.M.), and Dairy owners.

Findings from the household survey, key informant interviews, and study of building and thermal comfort were synthesised to develop the discussion content and guidelines for the next step of FGDs. The initial round of FGDs was planned along with social mapping and aimed at understanding community cooling needs in detail, mapping the available community resources, and exploring cooling hubs' possible governance mechanisms. Some FGDs were also planned with specific groups to understand sector-specific cooling needs. The second round of FGDs aimed to be conducted to share the needs assessment survey findings and the design options of potential cooling solutions to understand relevant governance issues, local capacity and resources needs, financing options, costs, and willingness to pay. The social mapping exercise was planned along with the first round of FGD to map community resources, cropping patterns, other sector-specific needs, and draw farm-tofork market processes. The sample sizes for the different methods of data collection are shown in Table 1. A team of architects also carried out a building typology assessment to understand the prevalent building construction practices and preferences in case study areas, including materials used for construction, reasons for selecting materials, sizes, and techniques. The assessment covered both public and residential buildings.

Table 1. The household survey sample.

\begin{tabular}{cccccc}
\hline Name of Cluster & Village Name & $\begin{array}{c}\text { Number of } \\
\text { Households }\end{array}$ & $\begin{array}{c}\text { Sample Size } \\
\text { Planned }\end{array}$ & $\begin{array}{c}\text { Village Wise No. of } \\
\text { HouseHolds Surveyed } \\
\text { (\%o of Total) }\end{array}$ & $\begin{array}{c}\text { Cluster Wise No. of } \\
\text { HouseHolds Surveyed } \\
\text { (\% of Total) }\end{array}$ \\
\hline \multirow{2}{*}{$>$ Koregaon, Satara } & Randullabad & 394 & 394 & $248(62.94)$ & $712(63.62)$ \\
& Karanjkhop & 725 & 725 & $464(64.00)$ & $53(19.27)$ \\
\hline \multirow{2}{*}{ Sinnar, Nashik } & Lonarwadi & 275 & 53 & $32(14.75)$ & $210(15.46)$ \\
& Bhatwadi & 217 & 32 & $125(14.43)$ & \\
\hline \multirow{2}{*}{ Yeola, Nashik } & Sonambe & 866 & 125 & $162(12.47)$ & $240(12.37)$ \\
& Patoda & 1299 & 162 & $1162(24.63)$ & $1162(24.63)$ \\
\hline
\end{tabular}

As FGDs and social mapping exercises could not be carried out due to the COVID 19 epidemic and induced restrictions, representatives and field workers of Bharatiya AgroIndustry Foundation (BAIF) and Yuva Mitra were interviewed on video calls to gather data, which was original to be gathered through these two data collection methods.

For the household survey, the census method was applied at Randullabad and Karanjkhop villages, Koregaon block, Satara District. In some cases, households were locked permanently for reasons such as families shifting to cities or other villages and seasonal migration for work. Additionally, some respondents refused to participate in the study; therefore, the final sample size was lesser than the sample size for Karanjkhop and Randullabad. One of the study's objectives was to test and propose appropriate methodologies to assess community cooling need. Data were collected in the Sinnar and Yeola cluster using a stratified sampling approach. The untimely outbreak of COVID 19 also imposed some restrictions on the mobility of data collectors. The stratification was done based on landholding data obtained from the Land Records office. From each of the strata, i.e., landless, small farmers (up to 3 acres); medium farmers ( $3-5$ acre); and big farmers (more than 5 acres), $10 \%$ representative samples were selected as presented in Table 2. 
Table 2. A stratified random sampling of Sinnar and Yeola block study villages.

\begin{tabular}{|c|c|c|c|c|c|}
\hline \multirow{2}{*}{ Village } & \multicolumn{4}{|c|}{ Landholding in Acres } & \multirow{2}{*}{ Total } \\
\hline & Landless & Up to 3 & 3 to 5 & More than 5 & \\
\hline Bhatwadi & 6 & 25 & 2 & 1 & 32 \\
\hline Lonarwadi & 6 & 42 & 4 & 3 & 53 \\
\hline Sonambe & 17 & 83 & 14 & 12 & 125 \\
\hline Patoda & 1 & 96 & 42 & 25 & 162 \\
\hline Dhulgaon & 1 & 51 & 27 & 1 & 78 \\
\hline
\end{tabular}

The meetings were done initially with a few community members and political representatives, with the purpose of this study explained (in advance) to obtain participants' consent for the study. Written consent from Gram Panchayat ward members was collected at the beginning of the study. During the household surveys, data collectors briefly explained the study's objective and obtained verbal consent from participants.

Due to the COVID 19 pandemic, the research team could not conduct the final set of FGDs with the community, though this was an essential step in the research design. The methodology was adapted, and discussions were continued with the partner organisations ${ }^{\prime}$ staff, who have been working in the study villages for a long time and hold a nuanced understanding of the village situation. The staff members were interviewed online. The interview guides used for these interviews are available in the Supplementary Materials.

\section{Results}

\subsection{Access to Healthy, Nutritious (and Socially Acceptable) Food}

In the Satara cluster, most households, including landless households, stated that they have nutritious food in sufficient quantity. About $4.7 \%$ of the landless households said they have enough food quantity, but the diversity of food is limited, and they had concerns about the adequacy of food throughout the year. Some households expressed that they have access to regular vegetarian diets throughout the year, but meat, fish, and fruits are unaffordable. While the surveyed households in the Satara cluster have not reported high levels of malnourishment or food scarcity, national nutrition surveys have pointed out the high degree of undernutrition and hidden hunger (inadequate micronutrients), as well as lack of awareness about malnourishment $[19,20]$. Undernourishment was reported among children and mothers in fewer than 10 families, including undernourished five children and four lactating mothers. However, children's nutrition may be inadequate, especially when considering the results of the Comprehensive National Nutrition Survey 2016-2018, or CNNS 5 [19].

\subsubsection{Barriers}

The study showed that fruits and vegetables are usually not included in mid-day meals in the schools and Anganwadis in the Satara cluster. In the Yeola cluster, the school staff try to add leafy and other vegetables; however, teachers struggle to procure ingredients. The school is considering shifting to central procurement, which will further shift the menu to dry rations.

\subsubsection{Potential}

The accessible cooling facility may help anganwadis and schoolteachers easily procure fruits and vegetables for mid-day meals. Cooling solutions, if provided, should be carefully linked to and planned for nutrition improvement among children [21]. In response to the domestic food and water-cooling questions, about $17-18 \%$ of households cluster reported a domestic refrigerator. About $70 \%$ of households in the Satara cluster said they do not need a refrigerator. The study showed that while cooling of food and water at home is not a felt need currently, additional cooling services to the community could improve nutritional status among children by making it easier for school and Anganwadi staff to 
add vegetables to the mid-day meals. The finding is consistent with Karlsson et al. [22], which showed that households with refrigerators could positively influence child health.

\subsection{Thermal Comfort for Living, Learning, Working, and Connectivity}

The respondents reported that the Satara region usually experiences one or more heatwaves between March to June that may last from 2-30 days. Several measures are adopted to cope with the summer heat, such as working on the farms early in the mornings or later in the evenings when it is cooler; using shaded areas, umbrellas, or a scarf; and taking more fluids like sugarcane juice or buttermilk. Construction techniques, building materials, opening sizes concerning room sizes, openings, and building orientation are essential in comfort building interiors. Passive cooling techniques-heat gain control and heat dissipation through building design to improve the indoor thermal comfort with low or no energy use, often found in traditional building structures-had traditional pitched roofs. The buildings also had traditional methods to dissipate warm air and take in cool air, such as adding a mezzanine floor with wooden flooring, incorporating ventilators, chimney shafts, and internal courtyards. It is found that building materials are used to keep the interior relatively cooler, such as Mangalore tiles and reinforced cement concrete (RCC) slabs for roofs, stone, brickwork with mud plaster for walls, and stone for flooring. Additionally, the buildings were orientated concerning the sun path to avoid heating and had appropriate window sizes for ventilation. The study shows that fans and table fans are most prevalent for space cooling, yet much below the national and state averages. Additionally, less than $2 \%$ of the houses had coolers, though about $25 \%$ were interested in buying a cooler, and 16\% wanted to buy fans.

\subsubsection{Barriers}

With economic development, housing stock in Karanjkhop and Randullabad has undergone a substantial change in the last ten recent years, with $38 \%$ of the houses in Karanjkhop and 72\% in Randullabad being reconstructed. With more disposable income, the households are using energy-intensive building materials, and there is an increased cooling demand for thermal comfort. Households with modest incomes have continued using traditional Mangalore tiles. In contrast, households with higher incomes demolished their old residences and converted them to structures with modern construction techniques and materials such as RCC slab aluminium sliding windows. Households with average/lower incomes are shifting to cheaper and durable materials such as asbestos cement sheets and galvanized iron (GI) sheets.

Building material or construction technology is composed of the cost of material/construction techniques, construction material availability, ease of maintenance, durability, and thermal comfort. The trend of change in building materials is likely to increase the demand for active cooling (heat-reducing mechanism typically with electronic devices). The study also shows that people are mainly unaware of heat stress impact on the heart, kidney, lungs, brain, and diabetes.

\subsubsection{Potential}

From building materials and design perspectives, India's Housing for All Programme, Pradhan Mantri Awas Yojana-Gramin (PMAY-G), has been limited in the project villages but provides an opportunity to strengthen climate-responsive architecture and usage of appropriate design and building materials for thermal comfort. There is a need and opportunity to develop the ecosystem, including trained masons and supply of materials. Furthermore, the Public Works Department, Govt of Maharashtra, recently included bamboo in the State Schedule of Rates. Such materials with high durability, ease of maintenance, lower costs, better thermal performance, locally sourced, and lower embedded energy should be explored.

From behavioural aspects, the availability of active cooling services and products may increase energy consumption, which may increase the carbon footprint unless powered by 
renewable sources. The consideration of high energy bills in part may keep the usage of cooling devices down to what is necessary. Therefore, promotion of practices including changes in diet; clothing; work schedules and lifestyles for summer months; passive cooling; and accessibility in terms of materials, costs, and trained human resources should accompany the expansion of active cooling for thermal comfort. An approach that combines behaviour changes, physiological acclimatisation, and passive and active cooling would lower the adverse impact of extreme heat on personal health and cooling service provision on the environment.

\subsection{Rural Livelihoods and Sufficiency of Income}

Over $80 \%$ of households in the Satara and Yeola cluster have agriculture as their primary income source. Work as agricultural labourers is a crucial income source for the landless and a supplementary source for smallholders.

As shown in Figure 3a, about 18 and 981 farmer households (69\% out of 1452 farmer households) sell their products to markets within $20 \mathrm{~km}$ in Satara. Only 207 (14\%) farmers sell their products to 80-90 km-range markets. Seventeen households use the existing cold storage among the surveyed population (no data available for 516 households), where 15 use cold storages within 90-103 km (Figure 3b). In terms of the produce, 16 and 1 farmer households, respectively, use the cold storage for potatoes and green peas. However, among the 1452 households, 41 and 229, respectively, farmers produce potatoes and green peas. The other agriproducts are common beans, sorghum, wheat, banana, Bengal gram, garlic, ginger, chilli, and onion. Depending on the farmers' produce and distance to sell their product, increased access to cold chain may elevate the farmers' income.

(a)

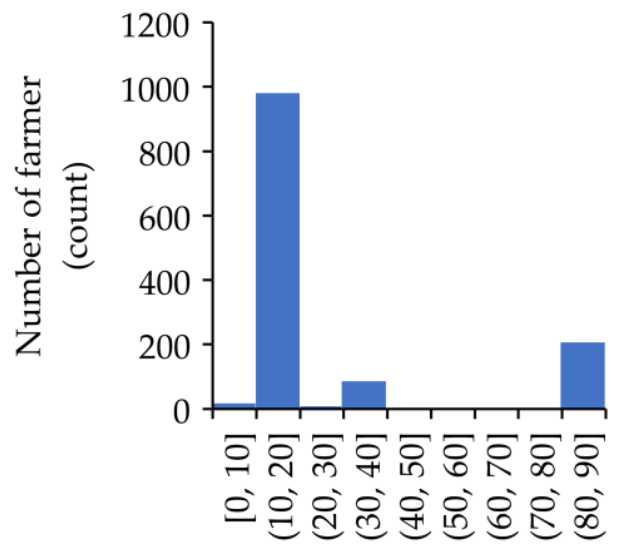

Distance to market range $(\mathrm{km}$ (b)

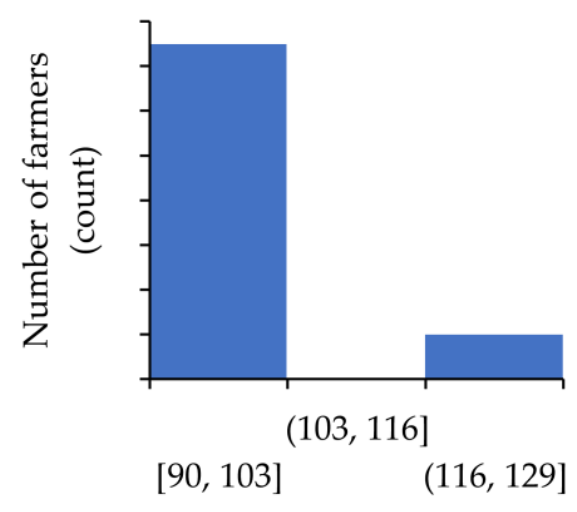

Distance from village to cold storage $(\mathrm{km})$

Figure 3. (a) Distance to market for Satara farmers; (b) distance from village to cold storage and number of farmers using them.

\subsubsection{Barriers}

Very few are engaged in businesses or employed in government or private jobs. About $70 \%$ of the households in Karanjkhop and 31\% in Randullabad reported per capita incomes less than INR 50,000. About $30.65 \%$ of families in Randullabad reported incomes of INR 50,000 to 1 lakh. Less than $1 \%$ of households in the Satara cluster have incomes over INR 5 lakh. Compared to the NABARD survey [23], most of the Satara cluster households are well below the average rural income. About $65 \%$ of the Satara cluster households are landless, marginal, or smallholder farmers, and about half of them practice rainfed farming. In the Yeola cluster, too, $58 \%$ and $65 \%$ of the farmers and marginal or smallholders.

Therefore, a significant number of households are landless or with marginal landholdings. About $65-75 \%$ of the households are landless, small, and marginal farmers, and 
the average household incomes in the Satara cluster are well below the national average incomes in rural households. Additionally, approximately $10-15 \%$ of the households face a range of scarcities and deprivations. These add up to a high degree of vulnerability to shocks and stresses and food security, which was also discussed by Goli et al. [24].

\subsubsection{Potential}

A facility such as a highly accessible and affordable $\mathrm{CCH}[16,17]$ could reduce some of these vulnerabilities. A highly accessible and affordable CCH could lead to:

- Higher incomes with the ability to secure better prices and better product quality with fresher fruits and vegetables;

- $\quad$ Better nutrition from greater crop diversity; and

- More significant equity with avoidance of losses that marginal farmers face.

\subsection{Agriculture and Horticulture}

Extreme weather conditions are impacting agriculture production and productivity. Around 34 farmers have experienced that standing crop is burnt due to intense sunlight, while 21 farmers feel that extreme summers cause a drought-like situation and scarcity of water for agriculture. About $69 \%$ said they tried to sell their produce immediately after harvest, even if this meant lesser bargaining power, as intense heat spoils the perishable produce. Within the sample of farmers who have incurred loss due to lack of storage, lack of transport, and fluctuation in market rates, marginal farmers have incurred more losses due to lack of transport compared to big farmers. Marginal and small farmers reported a loss in terms of quantity and cost.

In the Satara cluster, eight cold storage facilities were identified within $100 \mathrm{~km}$ of the cluster, of which four are close to Pune and situated near highways. The cold storage facilities in the cluster's vicinity are primarily used by traders, milk, and milk product companies. Less than $5 \%$ of the farmers reported using cold storages facilities. The farm produce is usually transported without refrigeration to Pune and Satara markets for one to two hours by motorised vehicles. Only seven farmers reported having used reefer vehicles to transport farm produce. The reasons for low usage of cold storage facilities by farmers include the cost of cold storage; the fact that only whole units are available for hire even if a lesser volume is needed; accessibility, convenience, cost of transport; and lack of awareness of benefits costs.

\subsubsection{Barriers}

Improved market linkages have been observed elsewhere to shift from bio-diverse mixed farming to cash crops and groundwater over-abstraction. Barriers also exist due to contract farming and more food miles with access to distant markets. Furthermore, there has been increased disparities among rural communities.

\subsubsection{Potential}

Around $85 \%$ of the farmers in the cluster believe that accessible and affordable cold storage facilities near the village will help them increase their bargaining power and fetch more profit. Farmers have expressed interest in exporting fruit crops such as strawberries, grapes, and pomegranate if reefer vehicles are readily available with established market linkages. Around $7 \%$ are unsure of such a facility's benefits, while $4 \%$ feel that it will not add to their net income. Increased incomes and buffers could be consciously used for gradual shifts to organic farming-Singh and Verma [25] showed increased availability would reduce the price of organic food from the point of view of the consumer and would also increase the size of the market- but organic farming is not currently prevalent in these clusters. 


\subsection{Dairy}

Like other rural parts of India, animal rearing_-bullocks, buffalos, mixed-breed cows, goats, sheep, and chickens-are parts of the local economy and livelihoods in the studied cluster. For some farmers, it is their main livelihood, while it is a supplementary income for others. Marginal, small, and medium-holder farmers own more cattle and goats than farmers with significant land holdings. Those with marginal landholdings own more goats than other animals.

Both dairies in Randullabad have bulk milk coolers installed. The collected milk is stored in bulk milk coolers at around $5{ }^{\circ} \mathrm{C}$. Milk producer companies have also provided diesel generator facilities to keep the chillers running during power failures. Milk dairies in Karanjkhop do not have bulk milk cooler facilities. Milk is collected early in the morning before 9 am and transported to the nearest cooling facilities in Pimpode village, $7 \mathrm{Km}$ from Karanjkhop. At Pimpode, the milk is cooled to $5^{\circ} \mathrm{C}$ and then transported to dairies in Titave village. There is a need to provide bulk milk coolers in Karanjkhop. The presence of a bulk milk cooler would lower the risk of milk spoilage and enhance incomes. Considering that the average annual income in Karanjkhop is about INR 50,000, for a household that maintains two mixed breed cows, producing $20 \mathrm{~L}$ of milk totally per day, the loss of the days earning of INR 640 is substantial. The investment needed is INR 150,000 for a bulk milk cooler, and the average monthly cost of electricity is around INR 12,000. The current demand for milk cooling and insulated transport is about $1875 \mathrm{~L}$ - the total daily mixed breed cow milk collection by four private dairies in Karanjkhop-including milk collected from a few neighbouring villages other than Randullabad.

Milk collection data in two dairies of Karanjkhop and Randullabad show that there is less milk collection during summer compared to milk collection in other seasons. Heat stress in summer has an impact on the production of milk. The summer to winter milk production ratio of Prayatna Dairy is 0.8 and of Hanuman dairy is 0.92 , indicating an $8 \%$ to $20 \%$ reduction in yield. As stated by animal keepers in the household survey, milk production estimates also show the same trends. Milk production is lowest in the summer and highest in winter. The summer to winter milk production ratio for cluster villages is 0.77 for buffalo, 0.78 for local breeds of cows, and 0.80 for mixed breed cows. The heat stress impact on milk production is almost equal on buffaloes and local and mixedbreed cows. Heat stress can also lead to a decrease in the number of days of lactation. However, interviews with staff in the cooperative dairy indicated that this had not been observed locally.

\subsubsection{Barriers}

Based on data collected from the milk cooling facility at Karanjkhop, there is a lack of conscious consideration of the benefits of cooling and the costs of not having cooling facilities within the village itself. There is also a lack of collectivism and community mobilisation in Karanjkhop, where a milk cooperative has not been formed so far. The business is conducted through private milk dairies.

\subsubsection{Potential}

If a milk cooler is made available, there is a possibility of enlarging the cattle herd to enhance incomes [26]. Milk chillers and other milk processing equipment, which would help avoid spoilage and add to dairy farming income [27], could be integrated within a $\mathrm{CCH}$. However, the decision to increase the livestock holding is related to space, shelter, water, feed, healthcare, human resources, and local demand and market linkages, besides financial investment. Currently, the bulk milk coolers in neighbouring Randullabad and the Pimpode collection centre are adequate.

\subsection{Meat}

People traditionally prefer to buy fresh meat in India, which suits the rural context as demand is predictable. Meat is eaten fresh on specific days; this is the general practice 
in rural areas, which may be consciously encouraged and continued. The Satara cluster has three meat shops that sell both meat (mutton and chicken) and eggs. In keeping with the practice of eating meat on specific days of the week, meat is not regularly available in these villages. The traditional practice for mutton sale is that meat shopkeepers usually assess the amount of mutton required a day in advance. Only the required number of animals are butchered, which is good practice for the local context as the villages' demand is predictable and waste is avoided. The meat shopkeepers buy goat and sheep locally from the same villages or Pimpode, Wai, Wathar. Around 400 goats and 500 sheep were being reared in the cluster villages at the survey time. Goat and sheep are sold locally as well as in distant markets.

People usually buy broiler chicken and fish from Pimpode or Wathar when they visit the weekly market. Randullabad has one poultry farm of broiler chickens of 6000 capacity. The chickens are supplied directly to Baramati Agro Pvt Ltd. At the time of the survey, around 239 chickens of local breeds were reared by 28 households in the cluster. Customarily, women rear chickens and the income from the sale of chickens and eggs also goes to the women. Local breeds of chickens are preferred in rural areas due to antibiotics and hormones in industrial poultry farms.

\subsubsection{Barriers}

Currently, lack of awareness and technical and financial capacity to run a modern slaughterhouse, processing unit, cold chain, and market links is a critical barrier for such enterprises.

\subsubsection{Potential}

The need to set up hygienic, advanced slaughterhouses near villages and transport meat to urban markets through effective cold chains may emerge more clearly if consumer preferences can be assessed, mainly to track if the demand in urban markets hygienic, trackable, packed meat has increased. A CCH, if developed, could integrate freezers for meat, which will also require the setting up of a modern slaughterhouse.

\subsection{Animal Shelters}

In the Satara cluster, animal keepers traditionally use different shelters, spaces, and practices for different seasons for cattle like a shed with a roof for the monsoons, open pens for the winter so that the animals can bask in the sun, or covering the animals with wet jute/cloth, frequently bathing them in the summer and installing fans and showers to cool them down. Traditional practices such as covering animals with wet jute/cloth (248 farmers), covering the shelter roofs with straw (250 farmers), or giving frequent baths to animals (301 farmers) are prevalent currently in the cluster villages. Very few farmers are use fans (six farmers) or showers for animals. At the poultry farm in Randullabad, tungsten lamps and tarpaulin covers are used during the winters for warming the space, and the roof is painted white during the summers to protect the chickens from extreme cold and heat, respectively. Tungsten lamps are installed in goat and sheep shelters as they easily catch pneumonia in the monsoon and winter.

The study also revealed that in the Satara cluster villages, in the past year, about 87 animals died due to extreme weather conditions such as heavy rain and high and low temperature. Goats are more prone to pneumonia during the rainy season. About 79 goats died because of heavy rain, while six cattle died due to extreme summer and winter. In the Yeola cluster, three cows and three goats died due to weather conditions. However, discussions with poultry keepers indicated no significant change in egg-laying quantities due to heat stress. Considering that the reduction in total yield is about 8-20\% less for mixed breed cattle and the average yield per day as $2500 \mathrm{~L}$ in the Satara cluster (Randullabad and Karanjkhop), the loss of income due to heat stress may range from INR 6200 to INR 15500 per day for the whole cluster. The economic loss (of an animal) can 
be substantial, as a single cow or buffalo's price may range from $5 \%$ to almost $40 \%$ of an average annual rural income.

Appropriate shelters that protect against extreme weather would reduce the yield losses and adverse health impacts of heat stress on livestock, which is especially relevant for stall-fed exotic or cross-bred cattle and even stall-fed rearing of local goat breeds such as Osmanabadi. Avoidance of diseases related to heat stress through temperature management would help reduce expenditure on animal healthcare.

\subsubsection{Barriers}

Currently, there is inadequate awareness about climate changes. While there may be general awareness about the impact of warm days and nights, it may not be perceived as acute enough for active measures beyond traditional practices. There is also an inadequate realisation of the quantum of loss. While there is awareness about a reduction in milk yields, there may not be a realisation of (and even research or documentation of) whether the trend of an increasing number of warm days and nights and more extreme temperatures has led to further milk reductions. Additional work is needed to bathe the animals more frequently. Additonally, the additional expenses for a fan or cooler may be difficult to afford for local people.

\subsubsection{Potential}

In the future, livelihood support schemes related to animal husbandry should take climate change considerations into account for management practices and shelter designs and animal breeding programmes to tolerate heat stress. Currently, when support has been facilitated to individual households for animal husbandry, the support may not necessarily include appropriate shelter. In Sinnar, as part of the effort to promote goat rearing, a central goat shed has been developed by Yuva Mitra and is designed following guidelines for ventilation and sunlight. However, assistance to individual households may only include the animals and the expenses of a shelter. Under the Navinya Purna Scheme, the Government of Maharashtra provides cows/buffaloes/goats/chicken to beneficiaries. The scheme budget includes provisions for the cost of the animals, sheds, fodder cutting machines, sheds for storing fodder, and insurance. A CCH could integrate animal shelters, which would help maintain the animals' productivity and reduce their health risks, thus reducing animal husbandry losses due to extreme heat.

\subsection{Animal Healthcare and Vaccines}

Livestock farmers, mainly smallholders, suffer from limited access to animal health services, training, and quality management [28], including ineffective cold chain services for animal vaccinations, low livestock productivity, and high levels of mortality reduction in income opportunities for farmers [29]. There is little to no cold chain logistics provided at the village level by district veterinary systems. Farmers are compelled to rely on private practitioners, incurring higher costs. Due to the remote areas of the market share, health services cannot achieve economies of scale. Cold chain services needed for vaccine maintenance require high costs. Since distribution becomes disaggregated and fragmented at delivery points, last-mile delivery is not profitable. The sector requires investments to tackle these challenges, specifically at the last-mile end of the supply chain.

In the study clusters, people use government as well as private animal healthcare facilities. A government veterinary hospital situated in Karanjkhop caters to five villages, namely, Karanjkhop, Moreband, Sonake, Jagtap Nagar, and Chawaneshwar. Traditional medicines and healthcare practices for animals are prevalent and help to a certain extent. However, with climate change, the patterns of spread of diseases among domesticated animals are also changing. For example, Bluetongue disease is relatively recent, and there may not be any locally known traditional medicines to treat it [30].

Several vaccines used in veterinary care require a cold chain to preserve efficacy, other than some like the vaccine for Newcastle disease, which is thermostable. The practice 
reported is that vaccines are administered to animals only if there is an outbreak of a particular disease in that region instead of as a preventive measure. Vaccines are available in local medical shops, and farmers have acquired knowledge of administering vaccines. Vaccines are reported to be carried in vaccine carriers for administration in field sites, but they may be carried on the person in clothing pockets in practice. The prevalent practice is for animal keepers to buy vaccines from local medical stores and administer these themselves. For short distances, typically, a vaccine carrier is not used. When the vaccine refrigerator at the veterinary hospital is not working, as was the case in one cluster, the practice is to store these in domestic refrigerators.

There have been deaths of 60 animals in cluster villages due to vaccine-preventable diseases. In the Satara cluster, some animals died despite being treated, while a few died due to non-treatment. The reasons for non-treatment include the non-availability of doctors and the incurability of the disease. As mentioned earlier, it is projected that pest and disease pressures among livestock would change in the coming decades, with global warming. As a risk mitigation measure, it is essential to strengthening veterinary healthcare services and animal vaccine cold chains.

\subsubsection{Barriers}

There is inadequate awareness about vaccine-preventable diseases among livestock keepers. A lack of licensed veterinary care staff as a veterinary license is needed to stock, sell, and administer vaccines. Cold chains are missing for animal vaccines, as are logistics of vaccine administration included among migratory populations.

\subsubsection{Potential}

The curriculum and legislations for Animal Health Workers are currently being developed [31]. Once these are notified and the skilling courses and testing systems implemented, the shortage of trained and licensed veterinary care staff is expected to be addressed over time. A CCH could integrate cold storage for animal vaccines and make ice packs for placement in vaccine carriers to transport the vaccines to the animal's herds, which would help reduce animal health risks and mortality and thereby avoid losses of income among animal keepers.

\subsection{Animal Breeding}

Though India has a large population of milk-producing animals/cattle, milk production per animal is considered low compared to varieties in temperate climates. The focus of state-supported animal breeding programmes in India in recent decades has primarily been to increase milk yield among cattle, and effectiveness of conversion to meat among chicken, while acknowledging the hardiness, heat tolerance, disease resistance, and other adaptations to local conditions among indigenous breeds.

$\mathrm{AI}$ facilities are provided by BAIF and government veterinary hospital. It is difficult to quantify the potential for improvement in terms of socio-economic well-being, but benefits include improved yields, higher income, and improved hardiness, resulting in reduced health costs. Costs include higher inputs of feed and care to amplify genetic improvement.

\subsubsection{Barriers}

The expense of setting up AI centres is high, despite being partially supported by the government. Supplying liquid nitrogen to remote areas and villages is particularly challenging. There is also a lack of demand from farmers. However, AI is provided to them for free because of farmers' perceptions about the higher level of care and inputs needed for cross-bred animals or non-acceptance AI. 


\subsubsection{Potential}

The future breeding strategy needs to be discussed following increased milk yield, climate resilience, heat stress tolerance, and disease resistance. For strengthening and accelerating breed improvement to enhance resilience, the following may need to be done:

- Deliberations with breeders, herders, animal husbandry depts, researchers, and extension workers about the need for and nature of breed improvement in the context of climate change;

- Selection of breeds and associated management practices;

- Outreach and participatory research; and

- Developing adapted cross-bred animals through traditional and modern methods, including AI and associated management practices and broader resource management arrangements.

If AI facilities are needed closer to the villages, a $\mathrm{CCH}$ could integrate a cold storage segment at the required temperature.

\subsection{Human Healthcare and Vaccine Cooling}

The rural health sector's cooling needs include cooling for vaccine - for routine vaccination programmes-storage, storage of medicines at the sub-centres/primary health centre (PHC)/rural hospital (RH), blood storage, and thermal comfort in health care setups. Health care services are provided by both public and private health care facilities. The national health infrastructure extends to the study clusters, including the universal immunization programme (UIP); Mission Indradhanush; and strengthening the Electronic Vaccine Intelligence Network (eVIN), which is a digital information system on the vaccine supply chain, stocks, and storage temperatures [32]. The National Family Health Survey-5 shows improvement in numbers of fully immunised children in the study clusters. Specific needs have emerged from the study, which may be addressed through government or private sector support.

Currently, the labour room at the PHC in the Satara cluster, primary health centre in Wathar station and rural hospital in Pimpode do not have air conditioning. The nearest blood bank is at Satara, $60 \mathrm{~km}$ away. The Rural Hospital and PHC procure blood in advance from Satara and store it in the medical supplies' refrigerator. A blood bank closer to the village clusters would help. Additionally, the ambulance is not air-conditioned.

\subsubsection{Barriers}

The National Cold Chain and Vaccine Management Resource Center (NCCVMRC) and National Cold Chain Resource Centre (NCCRC), Pune has made a significant effort to get at least one trained cold chain technician in every district of India. As a result, the Satara cluster has one trained cold chain technician. Despite the initiative, there is a lack of sufficient personnel trained in vaccine cold chain management, consistent with the study by Kim [33]. Implementation of the management systems and standard operating procedures designed by the NCCVMRC is lacking, along with backup systems for the vaccine cold storage facilities. Ice-Lined Refrigerators (ILRs) are used as backups, and if repair is delayed then stocks must be shifted to PHCs in adjoining areas.

\subsubsection{Potential}

A CCH could bring vaccine storage and administration closer to the villages, though this also requires preparedness for the cooling equipment's failure and extended power cuts.

\section{Discussion}

\subsection{Rural Cooling Services}

Based on our studies in Satara and Nashik, multi-functional CCHs could contribute to the community in several ways (Table 3). A range of underlying conditions, drivers, and barriers would need to be addressed in most sectors. The most widely prevalent and accessible cooling sectors in rural areas are: 
- Dairy, due to the development of dairy cooperatives and integrated supply chains;

- Domestic and workspace cooling by fans once electricity access has been enabled, while the changes in building materials and construction techniques are also likely rapidly driving up cooling demand, and there is a considerable lack of awareness about the health impacts of heat;

- The cold chain for the (human) vaccine is due to the tremendous push from the central government and associated agencies under the Universal Immunization Programme and the Extended Programme for Immunisation. The Covid 19 pandemic has also revealed the need to strengthen the human vaccine cold chain and energy backup systems. Trained staff, and procedures for dealing with power supply failures, are essential.

Table 3. Rural cooling services business potential.

\begin{tabular}{|c|c|c|c|}
\hline \multicolumn{3}{|c|}{ Cold Storage and Cooling Services } & Potential Customers/Partners \\
\hline & Mid-day meal & Fruits, vegetables, milk, and eggs storage & Anganwadi, School \\
\hline \multirow{3}{*}{\multicolumn{2}{|c|}{ Retail and home food }} & Fruits, vegetables, milk, eggs, and chocolates & \multirow{3}{*}{ Shop owner/shop keeper/households } \\
\hline & & Chilled water, cold drinks, & \\
\hline & & meat, and ice-cream & \\
\hline & Seed storage & Long duration storage of seeds & Individual farmers/FPO \\
\hline & Coolhouse & Cool space to grow mushrooms & Individual farmers \\
\hline & Packhouse & $\begin{array}{l}\text { Table and shelving space hire for sorting, } \\
\text { grading, and packing of fruits and vegetables }\end{array}$ & Individual farmers/FPO \\
\hline & Fruit and vegetable store & Day, week, and month-wise storage & Individual farmers \\
\hline & Food processing & Processing, storage & FPO/ SHG/ entrepreneurs \\
\hline & \multirow{2}{*}{ Dairy } & Bulk milk cooler & \multirow{2}{*}{ Dairy Cooperative } \\
\hline & & Dairy processing plant & \\
\hline & Eggs & Storage & Individual poultry farmers \\
\hline & \multirow{2}{*}{ Meat } & Slaughterhouse, packaging & \multirow{2}{*}{ Animal keeper's cooperative } \\
\hline & & Storage & \\
\hline & Artificial insemination (AI) & AI straws storage & BAIF \\
\hline & \multirow{2}{*}{$\begin{array}{l}\text { Vaccine and medical } \\
\text { supply store }\end{array}$} & Animal vaccine storage & Pharmacist \\
\hline & & Human vaccine, blood, and medical supplies & PHC/Dept of Health \\
\hline & \multirow{2}{*}{ Vaccine icepacks } & Icepacks for animal vaccine carriers & Pharmacist \\
\hline & & Icepacks for human vaccine carriers & Health Dept \\
\hline & \multirow{4}{*}{ Space/District cooling } & Health facility cooling & Health Dept \\
\hline & & Community space cooling & Gram Panchayat \\
\hline & & Anganwadi space cooling & Gram Panchayat/ICDS Dept \\
\hline & & Homes and workspaces (e.g., banks) & Individual homes and entities \\
\hline & \multirow{3}{*}{ Vehicle cooling } & Private transport cooling & Individual users \\
\hline & & Public transport cooling & MSRTC, operators \\
\hline & & Para-transit cooling & Operators \\
\hline & \multirow{2}{*}{$\begin{array}{l}\text { Emergency supplies } \\
\text { elihood }\end{array}$} & Storage of rations, medical supplies & Gram Panchayat \\
\hline Likel & & High & Needs further discussion \\
\hline
\end{tabular}

Agriculture packhouses and cold storages are recognised as necessary by farmers. However, the lack of active promotion and development of appropriate sizes, accessibility, business models, financial support, and market linkages have been barriers to such facilities being set up according to farmers' needs. Apart from saving produce that may otherwise perish, cold stores could also enable time buffers to wait till prices are comparatively better. Packhouses and agri-produce cooling facilities close to the villages would improve children's nutritional status since adding vegetables to the mid-day meal may become much easier for schools.

The current preference for and practice of fresh meat consumption in villages avoids the need for cooling for local consumption of meat. However, the growing demand for hygienic meat in urban areas could grow the market in the future, which may drive the need to set up modern slaughterhouses and transport refrigeration to reach distant markets. 
The cooling needs around animal husbandry (other than milk chilling and processing) present a mixed situation. Certain traditional practices of keeping animals cool are generally followed, but animal shelters with cooling mechanisms integrated are not prevalent. The cold chains for animal vaccines appear to be sub-optimal. The underlying reasons may be vaccines' cost and the lack of trained and authorised animal healthcare workers to administer vaccines. The COVID-19 pandemic also revealed the importance of life-boats to keep stocks of emergency supplies of medical needs, food, and other essentials. A community-scale cooling service may help fulfil the cooling needs of the diverse sectors in rural communities while increasing resilience and preparedness to withstand unexpected external shocks, whether they be weather-related or pandemic, political or economic shocks.

\subsection{Community Cooling Hub (CCH): Conceptual Framework}

Presently, the cooling system and supply chain providing cooling to domestic, agricultural vaccination sectors work separately. The community's cooling needs are addressed in a fragmented manner or sector-wise as the sectors' governance rests with state governments' multiple departments. For example, post-harvest agriculture needs are addressed through farm produce cold storages/packhouses, and vaccine preservation needs are addressed through providing deep freezers and vaccines carriers at primary health centres. The reductionist sub-system-focused approach neglects the interdependencies between economic decisions; available energy resources; technology choices; climate change mitigation and adaptation strategies; and social, cultural and political systems, resulting in a sub-optimal outcome. There is a need to take a system-of-systems approach, which lies at the core of the $\mathrm{CCH}$ concept (initially conceptualised in [34-36]), to cooling provision rather than using siloed strategies, which only deliver quick incremental efficiency wins to meet the surging cooling demand in an economically, environmentally, and socially sustainable manner. This approach also supports the wider energy system decarbonisation by creating more intermittent renewable energy sources through thermal energy storage systems, harnessing thermal resources, reducing the investment need for increased power grid and generation capacity, and reducing peak energy demand. The $\mathrm{CCH}$ concept envisions understanding, concurrently, a range of different cooling needs related to agriculture and post-harvest, animal husbandry, health, (building) thermal comfort, transport, and others, to enable the design and management of more integrated and synergistic solutions of governance, enterprise, economy, energy, and materials [16,34]. By estimating cooling needs more accurately and developing cooling solutions for different needs in an integrated manner, it is possible to increase access to cooling and enhance the associated well-being with minimal greenhouse gas emissions (GHG) emissions and carbon footprint.

The first step in designing such a cooling (as a service) model is understanding the sector-wise cooling needs and quantum of those needs. Aimed to calculate sector-specific cooling needs of rural communities in India, our study is set out to test a cooling needs assessment methodology (a refined version of [37]) in a rural context. The methodology developed by and refined in partnership with two non-profit organisations, BAIF, Pune and Yuva Mitra, and Nashik, encompasses several years of experience in the rural development sector, especially agriculture and animal husbandry. Both of the organisations worked in the two clusters identified as the study area. The needs assessment included their quantum of cooling demand, current use, and different ways the communities seek to maintain or enhance this cooling level to meet their health, economic, and comfort needs. The portfolio of cooling needs (for food, health, and thermal comfort) identified through this study will be utilised to develop a cooling solution catering to the demand, aggregate cooling provision, and harness localised waste and renewable sources of thermal energy to provide environmentally friendly and affordable cooling for all. Cooling technologies, products, and services are spread across different sectors of the economy such as residential and commercial buildings, cold chains for vaccines, agriculture produce, food products, household and commercial refrigeration, and transportation. 
The $\mathrm{CCH}$ can provide a chilled space for pre-cooling, which reduces the losses and prevents 'overheating' of cold storage and transport equipment, food packing, processing, and manufacturing, adding value to the product and extending shelf-life. The $\mathrm{CCH}$ can offer personal refrigerated lockers accessible to village home-keepers, deliver the cooling for a community hall with a safe temperature environment, serve as a crèche for the infants of the village or a shelter for the elderly, provide a schoolroom for classes on the hottest days of the year, and function as life-boats in times of disaster (Figure 4). All these additional services can be provided efficiently and sustainably by CCHs in an aggregated manner, with a stack of revenues reducing the economic and environmental cost of cooling. The portfolio of services can be expanded with the integration of thermal energy storage systems, which would enable capturing excess cold produced during off-peak cooling demand periods, and recovering waste heat from cooling equipment into co-located services, such as food drying, cooking and processing of hot water for cleaning and washing applications, or rerouting excess thermal energy to individual homes as an off-grid energy supply mechanism for cooling or hot water provision. It can also provide an opportunity to meet various rural cooling needs in outreach areas, such as pre-cooling of produce and vaccine storage during mobile/outreach campaigns. CCHs are envisaged as facilities that are highly accessible to villages or village clusters, managed by local entities, that meet diverse local cooling needs in an aggregated manner to enhance well-being while optimising energy and resource management and potentially bundling multiple revenues streams. The expectation is that CCHs can support farmers and fishers in reducing post-harvest food loss; protecting and adding quality and value of produce by food processing and manufacturing; providing new market connectivity; and ensuring that communities have continuing access to lifesaving vaccines, domestic cooling, and adequately cooled health facilities and community services. Through access to cooling in a rapidly warming world, the long-term outcomes expected include improved incomes; resilient livelihoods and other well-being dimensions for rural communities; and reduced emissions and wastage in food production, transport, and storage.

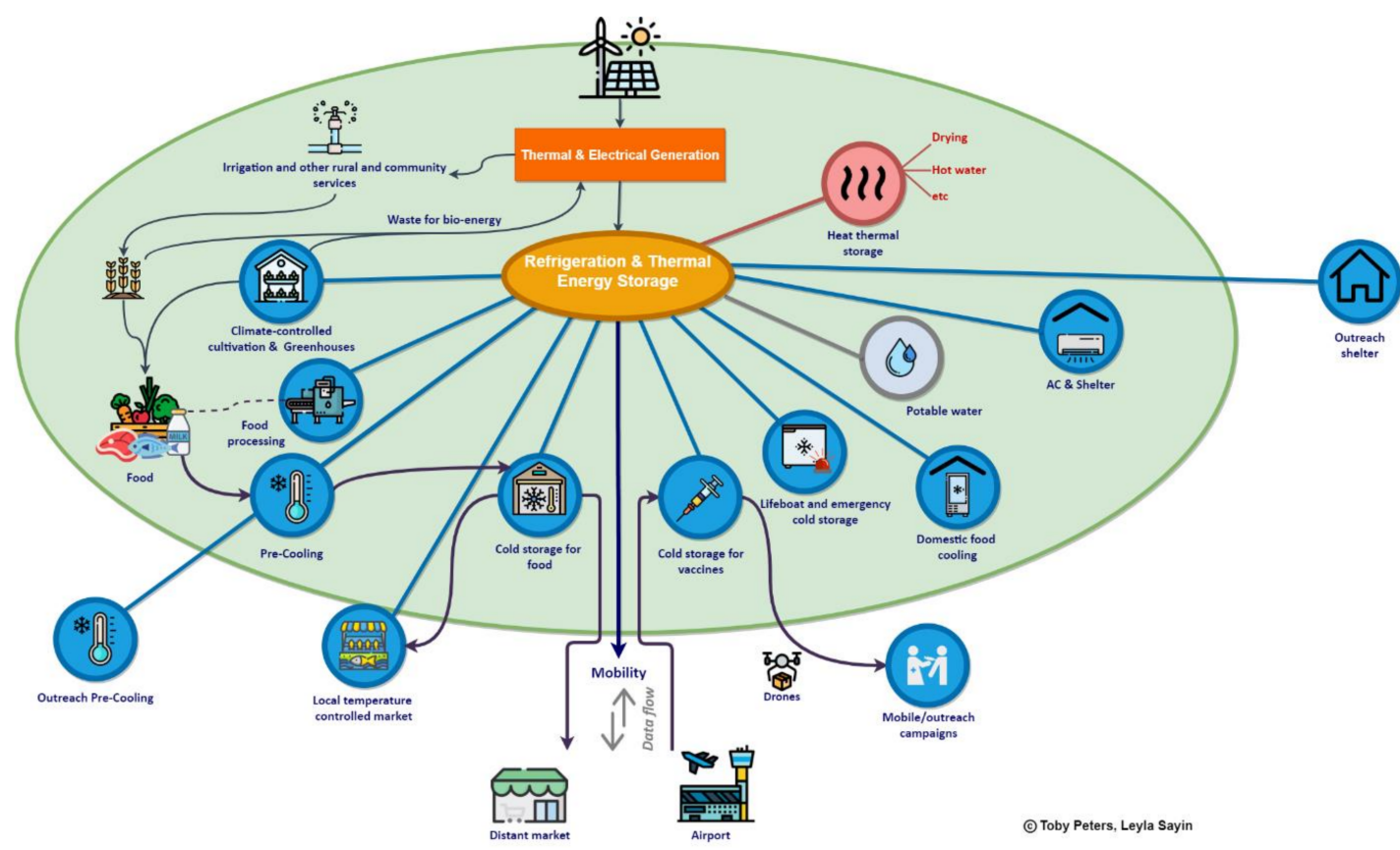

Figure 4. Community cooling hubs (CCH) framework. Energy sources, irrigation, food processing, greenhouse, pre-cooling, potable water, vaccine, emergency cold storage, AC, domestic food cooling, and distant market: icons made by Freepik from www.flaticon.com. Food: icons made by photo3idea studio \& Freepik from flaticon.com. Cold storage: icon made by phatplus from flaticon.com. Local temperature controlled market: icon made by wanicon from flaticon.com. Drone: icon made by Pixel perfect from flaticon.com. Airport: icon made by Pause08 from flaticon.com. Mobile/outreach campaign: icon by Adioma. 
Cooling also has an intertwined relationship with sustainable development goals (SDGs) - these include ending poverty; zero hunger; good health and well-being; gender equality; affordable and clean energy; decent work; economic growth; improving industry, innovation, and infrastructure; reducing inequality; sustainable cities, and communities; responsible consumption; and production and climate action.

The India Cooling Action Plan of the Ministry of Environment, Forest, and Climate Change has the vision to provide sustainable cooling and thermal comfort for all while securing environmental and socio-economic benefits for society through integrated solutions with synergies in actions towards providing cooling solutions across sectors [8]. The proposed $\mathrm{CCH}$ may provide an integrated solution for rural contexts in developing countries.

\section{Conclusions}

The study aimed to understand how rural communities are meeting their nutrition, livelihood, health, living space, and mobility requirements concerning the role of cooling. The objective was to assess how cooling could enhance well-being, provide access, and minimise environmental footprint. Rich narratives and datasets have been gathered that provide insights into the different ways the natural resource base could be enhanced while improving communities' comfort and resilience with a range of cooling technologies. The information gathered also has pointers to the fragility of the social-ecological-environmental complex, especially in the face of climate change and impending increases in mean temperatures and extreme heat events. These provide an impetus to go further with the studies initiated over the last few months. Our analysis on Satara and Nashik showed multi-functional CCHs could contribute to different sectors, especially agriculture (fruit and vegetables), dairy, building (residential and commercial space cooling), and healthcare (vaccine cold storage) at present, and that they have potential for other sectors. The farmers recognised agriculture packhouses and cold storages. However, constraints such as the lack of active promotion and development of appropriate sizes, accessibility, business models, financial support, and market linkages act as barriers. Apart from saving produce that may otherwise perish, cold stores could also enable time buffers to wait until prices are better than the current market and increase farmers' income. Furthermore, packhouses and agri-produce cooling facilities-close to the villages-would improve children's nutritional status, since adding vegetables to the mid-day meal may become much easier for schools. Integrated with thermal energy storage systems, $\mathrm{CCHs}$ would also unlock otherwise redundant renewable or waste energy resources; aid in scaling up the use of intermittent renewable sources, such as solar and wind; and boost system flexibility by enabling cold to be used where and when needed.

Supplementary Materials: The following are available online at https:/ / www.mdpi.com/article/10 $.3390 /$ su13105595/s1.

Author Contributions: Writing—original draft, K.B.D., X.W., T.P., and S.M.; data analysis, S.M., S.A., G.P., N.W., M.P., and P.S.; methodology design, T.P., K.B.D., X.W., S.M. M.P., and S.A.; fieldwork and data collection, N.W., G.P., and P.S.; writing-review and editing, T.P., K.B.D., X.W., and S.M. All authors have read and agreed to the published version of the manuscript.

Funding: This research was funded by Shakti Sustainable Energy Foundation, grant number G19 SSEF 436.

Institutional Review Board Statement: Not applicable.

Informed Consent Statement: Informed consent was obtained from all subjects involved in the study.

Data Availability Statement: The data presented in this study are available on request from the corresponding authors. The data are not publicly available due to potential project development requirements of the concerned communities and research partners. 
Acknowledgments: The authors wish to acknowledge the technical and fieldwork coordination support from Baswant Dhumane from Centre for Environment Education; Ameya Kekare from Studio Indesign; Sneha Shinde and Sandip Pawar from BAIF (Pune); and Abhishek Rawat from Yuva Mitra. We would like to thank the participants who have provided information in household surveys, interviews, and focus group discussions. The authors also wish to thank Leyla Sayin and Tim Fox for their assistance with reviewing the manuscript.

Conflicts of Interest: The authors declare no conflict of interest.

\section{References}

1. SEforAll. Chilling Prospects: Providing Sustainable Cooling for All. 2018. Available online: https://www.seforall.org/sites/ default/files/SEforALL_CoolingForAll-Report.pdf (accessed on 11 May 2021).

2. Kovats, S.; Hajat, S. Heat stress and public health: A critical review. Annu. Rev. Public Health 2008, 29, 41-55. [CrossRef] [PubMed]

3. Mbow, C.; Rosenzweig, C.; Barioni, L.; Benton, T.; Herrero, M.; Krishnapillai, M.; Liwenga, E.; Pradhan, P.; Rivera-Ferre, M.; Sapkota, T.; et al. Food Security. In Climate Change and Land: An IPCC Special Report on Climate Change, Desertification, Land Degradation, Sustainable Land Management, Food Security, and Greenhouse Gas Fluxes in Terrestrial Ecosystems; Shukla, P.R., Skea, J., Calvo Buendia, E., Masson-Delmotte, V., Pörtner, H.O., Roberts, D.C., Zhai, P., Slade, R., Connors, S., Van Diemen, R., et al., Eds.; IPCC: Geneva, Switzerland, 2019; in press; Available online: https://www.ipcc.ch/site/assets/uploads/sites/4/2020/02/ SRCCL-Chapter-5.pdf (accessed on 11 May 2021).

4. Dunne, J.P.; Stouffer, R.J.; John, J.G. Reductions in Labour Capacity from Heat Stress under Climate Warming. Nat. Clim. Chang. 2013, 3, 563-566. Available online: https:/ / www.nature.com/articles/nclimate1827 (accessed on 11 May 2021). [CrossRef]

5. Kigali Amendment. Kigali Amendment to the Montreal Protocol on Substances that Deplete the Ozone Layer. Kigali. 15 October 2016. Available online: https://ozone.unep.org/treaties/montreal-protocol/montreal-protocol-substances-deplete-ozone-layer (accessed on 11 May 2021).

6. Debnath, K.B.; Jenkins, D.P.; Patidar, S.; Peacock, A.D. Understanding Residential Occupant Cooling Behaviour through Electricity Consumption in Warm-Humid Climate. Buildings 2020, 10, 78. Available online: https://www.hindawi.com/journals/js/2016/6 070742/ (accessed on 11 May 2021). [CrossRef]

7. Kjellstrom, T.; Briggs, D.; Freyberg, C.; Lemke, B.; Otto, M.; Hyatt, O. Heat, Human Performance, and Occupational Health: A Key Issue for the Assessment of Global Climate Change Impacts. Annu. Rev. Public Health 2016, 37, 97-112. [CrossRef] [PubMed]

8. India Cooling Action Plan. 2019. Available online: http:// ozonecell.nic.in/wp-content/uploads/2019/03/INDIA-COOLINGACTION-PLAN-e-circulation-version080319.pdf (accessed on 11 May 2021).

9. Assessment of Climate Change over the Indian Region. In Assessment of Climate Change over the Indian Region; Springer Science and Business Media LLC.: Berlin/Heidelberg, Germany, 2020.

10. Wasti, S.; Sah, N.; Mishra, B. Impact of Heat Stress on Poultry Health and Performances, and Potential Mitigation Strategies. Animals 2020, 10, 1266. [CrossRef] [PubMed]

11. Chand, K.K. Animal Healthcare Industry in India: Trends and Challenges. J. Agroecol. Nat. Resour. Manag. 2019, 6, 3943. Available online: https://www.krishisanskriti.org/vol_image/14Jul201908074006\%20\%20\%20\%20\%20\%20\%20Kapil\%20 Kumar\%20Chand\%20\%20\%20\%20\%20\%20\%20\%2039-43.pdf (accessed on 11 May 2021).

12. Nawab, A.; Ibtisham, F.; Li, G.; Kieser, B.; Wu, J.; Liu, W.; Zhao, Y.; Nawab, Y.; Li, K.; Xiao, M.; et al. Heat stress in poultry production: Mitigation strategies to overcome the future challenges facing the global poultry industry. J. Therm. Biol. 2018, 78, 131-139. [CrossRef] [PubMed]

13. Kumar, S.; Sachar, S.; Kachhawa, S.; Goenka, A.; Kasamsetty, S.; George, G. Demand Analysis of Cooling by Sector in India in Alliance for an Energy Efficient Economy. 2018. Available online: https:/ / aeee.in/projects/demand-analysis-for-cooling-bysector-in-india-in-2027/ (accessed on 11 May 2021).

14. Committee for Doubling Farmers' Income. Report of the Committee for Doubling Farmers' Income. In Post-production Agri-logistics: Maximising Gains for Farmers: Vol. III; Department of Agriculture, Cooperation and Farmers' Welfare, Ministry of Agriculture \& Farmers' Welfare, Govt of India: New Delhi, India, 2017. Available online: https://agricoop.gov.in/sites/default/files/DFI\%20 Volume\%203.pdf (accessed on 11 May 2021).

15. Wang, X.; Day, R.; Murrant, D.; Marín, A.D.; Botello, D.C.; González, F.L.; Radcliffe, J. A Capabilitiesled Approach to Assessing Technological Solutions for A Rural Community. Energies 2021, 14, 1398. Available online: https:/ /www.mdpi.com/1996-1073/ 14/5/1398 (accessed on 11 May 2021). [CrossRef]

16. MPEnSystems Advisory Pvt Ltd. University of Birmingham, \& Shakti Sustainable Energy Foundation, 2019. Promoting Clean and Energy Efficient Cold-Chain in India. Available online: https://shaktifoundation.in/report/promoting-clean-and-energyefficient-cold-chains-in-india-2/ (accessed on 11 May 2021).

17. Fox, T. Community Cooling Hubs: A Route to Sustainable Economic Development. Agric. Dev. 2019, 36, 6. Available online: https:/ / www.cabi.org/nutrition/abstract/20193201965 (accessed on 11 May 2021).

18. NCCD. All India Cold-chain Infrastructure Capacity (Assessment of Status \& Gap). 2015. Available online: https://nccd.gov.in/ PDF/CCSG_Final\%20Report_Web.pdf (accessed on 11 May 2021). 
19. Ministry of Health and Family Welfare, Government of India, UNICEF, \& Population Council. Comprehensive National Nutrition Survey (CNNS) 2016-2018: National Report. 2019. Available online: https://nhm.gov.in/WriteReadData/1892s/14057960315712 01348.pdf (accessed on 11 May 2021).

20. Raghunathan, K.; Headey, D.D.; Herforth, A. Affordability of nutritious diets in rural India. In Affordability of Nutritious Diets in Rural India; International Food Policy Research Institute: Washington, DC, USA, 2020.

21. UNICEF. The State of the World's Children Children, Food and Nutrition: Growing Well in a Changing World; UNICEF: New York, NY, USA, 2019; Available online: https:/ / www.unicef.org/media/61871/file/SOWC-2019.pdf (accessed on 11 May 2021).

22. Karlsson, O.; Kim, R.; Joe, W.; Subramanian, S. The relationship of household assets and amenities with child health outcomes: An exploratory cross-sectional study in India 2015. SSM Popul. Health 2020, 10, 100513. [CrossRef] [PubMed]

23. NABARD All India Rural Financial Inclusion Survey 2016-17. 2018. Available online: https://www.nabard.org/auth/ writereaddata/tender/1608180417NABARD-Repo-16_Web_P.pdf (accessed on 11 May 2021).

24. Goli, S.; Rammohan, A.; Reddy, S.P. The interaction of household agricultural landholding and Caste on food security in rural Uttar Pradesh, India. Food Secur. 2021, 13, 219-237. [CrossRef]

25. Singh, A.; Verma, P. Factors influencing Indian consumers' actual buying behaviour towards organic food products. J. Clean. Prod. 2017, 167, 473-483. [CrossRef]

26. Belsare, P.V.; Pandey, V. Management of Heat Stress in Dairy Cattle and Buffaloes for Optimum Productivity. J. Agrometeorol. 2008, 10, 365-368. Available online: https:/ / www.academia.edu/30940023/Management_of_heat_stress_in_dairy_cattle_and_ buffaloes_for_optimum_productivity (accessed on 11 May 2021).

27. Edwin, M.; Sekhar, S.J. Techno-Economic Studies on Hybrid Energy Based Cooling System for Milk Preservation in Isolated Regions. Energy Convers. Manag. 2014, 86, 1023-1030. Available online: https://www.sciencedirect.com/science/article/abs/pii/ S0196890414006001 (accessed on 11 May 2021). [CrossRef]

28. Leitch, H.; Abhinav, G.; Bihari, B. Building Last Mile Livestock Extension Services for Rural Communities in Jharkhand, India (No. 12; South Asia Agriculture and Rural Growth Discussion Note Series); World Bank: Washington, DC, USA, 2020; Available online: http:/ / documents.worldbank.org/curated/en/329431591190384738/Building-Last-Mile-Livestock-Extension-Servicesfor-Rural-Communities-in-Jharkhand-India (accessed on 11 May 2021).

29. FAO. World Livestock: Transforming the Livestock Sector through the Sustainable Development Goals. 2018. Available online: http: / / www.fao.org/3/CA1201EN/ca1201en.pdf (accessed on 11 May 2021).

30. Saminathan, M.; Singh, K.P.; Khorajiya, J.H.; Dinesh, M.; Vineetha, S.; Maity, M.; Rahman, A.F.; Misri, J.; Malik, Y.S.; Gupta, V.K.; et al. An updated review on bluetongue virus: Epidemiology, pathobiology, and advances in diagnosis and control with special reference to India. Veter. Q. 2020, 40, 258-321. [CrossRef] [PubMed]

31. ASCI Transnational Skill Standards for Agriculture Industry. Indian Standards Banchmarked to UK Standards; Agriculture Skill Council of India (ASCI): Haryana, India, 2016; Available online: https:/ /ink.springer.com/content/pdf/10.1007\%2F978-981-154327-2.pdf (accessed on 11 May 2021).

32. Gurnani, V.; Singh, P.; Haldar, P.; Aggarwal, M.K.; Agrahari, K.; Kashyap, S.; Ghosh, S.; Mohapatra, M.K.; Bhargava, R.; Nandi, P.; et al. Programmatic assessment of electronic Vaccine Intelligence Network (eVIN). PLoS ONE 2020, 15, e0241369. [CrossRef] [PubMed]

33. Kim, Y.E. Determinants of childhood vaccination in Nagaland, India: A cross-sectional study with multilevel modelling. BMJ Open 2021, 11, e045070. [CrossRef] [PubMed]

34. Peters, T. A Cool World: Defining the Energy Conundrum of Cooling for All; University of Birmingham: Birmingham, UK, 2020; Available online: https:/ / www.sustainablecooling.org/wp-content/uploads/2020/04/8422-UofB-A4-Report-master-324pp_ ST2_accessible.pdf (accessed on 11 May 2021).

35. Peters, T. The Clean Cold Chain in Agriculture in Developing Countries; Editorial; Agriculture for Development: Clean Cold Chain in Agriculture; Tropical Agriculture Association. Number 36. 2019, pp. 2-3. Available online: https://taa.org.uk/wpcontent/uploads/2019/04/Ag4Dev36_web_version.pdf (accessed on 11 May 2021).

36. Ogden, C. University of Birmingham Develops 'Cooling Hubs' to Reduce Food Waste. Environ. J. 2019. Available online: https: / /environmentjournal.online/articles/university-of-birmingham-develops-cooling-hubs-to-reduce-food-waste/ (accessed on 11 May 2021).

37. Peters, T.; Bing, X.; Debhath, K.B. Cooling for All: Needs-Based Assessment: Country-Scale Cooling Action Plan Methodology. 2020. Available online: https:/ / www.sustainablecooling.org/wp-content/uploads/2020/06/Needs-Assessment-June-2020.pdf (accessed on 11 May 2021). 